\title{
A compreensão da sociedade da informação
}

\section{M aria A lice G uimarães B orges}

Professora do D epartamento de Ciência da Informação e D ocumentação da U niversidade de Brasília; mestre em Ciência da Informação.

E-mail: malice@unb.br

\section{Resumo}

Este artigo trata do contexto de mudança na sociedade da informação e do conhecimento, das tendências atuais das organizações e do desafio da compreensão desse momento através do "conhecimento objetivo", dentro de uma visão integrada de seus problemas e soluções, como uma oportunidade para se conseguir uma análise estrutural e conjuntural.

\section{Palavras-chave}

Sociedade da informação; Sociedade do conhecimento; Perspectivas da sociedade da informação; Enfoque sistêmico; Conhecimento objetivo.

\section{The understanding of information and knowledge society (IKS)}

\begin{abstract}
This paper aims at understanding the changing context of the Information and Knowledge Society (IKS). Present trends in information organizational structures are examined for an understanding both of these developments and their environment. An integrated view of problems and alternative solutions is given to obtain a structured and contextual analysis.
\end{abstract}

\section{Keywords}

Information society; Knowledge society; Information society perspectives; System analysis; Objective understanding.

\section{INTRODUÇÃO}

D entro deum contexto de mudança da sociedadeindustrial para a sociedade da informação e do conhecimento, este documento tem o propósito de entender como as ciências, a ciência da informação e da comunicação, as novas tecnologias, dentro de uma abordagem macro, sistêmica, poderão ajudar não somente na compreensão do mundo, mas também na solução dos problemas, muitas vezes elementares, que atingem o ser humano. Problemas estes que o levam a uma condição não só de miserabilidade, mas também de exclusão da sociedade e das oportunidades de sobrevivência digna, da possibilidade de ser feliz.

A presenta algumas ten dências e os desafios do momento, indicando que uma visão integrada do mundo moderno, dos seus problemase soluções, juntamente com os resultados e avanços dasciências, das tecnologias, da vontade política dos dirigentes, aliados às ferramentas capazes de organizar a complexidade e a produzir resultados, e com a determinação do homem, poderão encontrar, na sociedade da informação e do conhecimento, alternativas para diminuir os problemas da vida humana, das organizações e da sociedade, neste século que se inicia, pois como afirma a professora Rosa M aria Vicari (2000) da UFRGS:

"A Sociedade da Informação cresce rapidamente. No momento, não há falta de visões sobre o futuro - somente escolher as certas é que é difícil."

\section{O CONTEXTO DA MUDANÇA}

Tanto no cenário mundial quanto no do Brasil, vive-se uma palavra de ordem que cerca, impulsiona, agride e até sufoca o indivíduo. Esta palavra é M U DA N ÇA .

V ivencia-se uma nova ordem que tem suas bases nas mudanças paradigmáticas por que passa este fim de século, tanto do ponto de vista social, econômico, cultural, político, tecnológico e outros.

V ários autores têm elaborado documentos, artigos, livros sobre esta nova era, buscando a compreensão dos vários ângulos dessas mudanças.

Kenneth Boulding em 0 significado do século XX classifica a vida humana em duas grandes épocas: a pré-civilizada, do nômade que adquire caracteres de civilização ao urbanizarse, e a pós-civilizada, que constitui a atual, e afirma: "A grande transição não é somente algo que afeta a ciência, a tecnologia, o sistema físico da sociedade o o aproveitamento da energia. É também a transição das instituições sociais". 
Esta transição é o reflexo de uma mudança, de uma transformação, da passagem de um estágio a outro, enfim da conversão de uma determinada situação a uma nova, hoje denominada "mudança de paradigma", levando a novas exigências, estratégias e ações.

A o longo deste século a ciência propôsuma nova maneira de se pesquisar, estudar e compreender o mundo, suas especificidades e suas relações, como mostram as duas representações de M attos (1982) apresentadas a seguir.

Partimos do período da "especialização" que também deu sua colaboração ao estudo das ciências, possibilitando entrar no âmago de cada uma delas ou de suas disciplinas, por meio da decomposição de seus vários aspectos, utilizando-se da classificação, da análise, da enumeração etc.

\section{FIGURA 1}

\section{A bordagem tradicional geral}

ABORDA GEM TRA DICIONAL GERA L

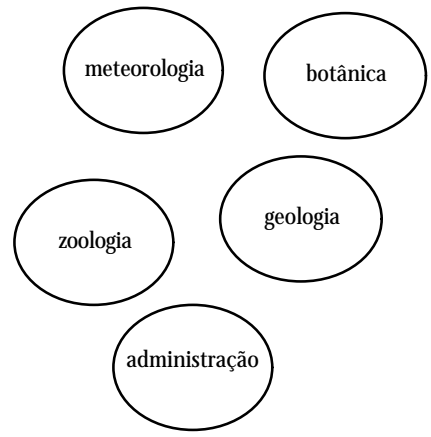

NÍVEL DO ISO LADO

Componentes relativamente homogêneos.

- A delimitação do campo de estudo se faz em função da natureza física dos elementos estudados.

- Estudam-se, de forma casuística, as relações de causa e efeito

$\mathrm{A} \rightarrow \mathrm{B}$ (relação orientada)

D essa época da especialização, do isolamento, da análise como fim em si mesma e cada vez mais atomística, chegouse à era da síntese, do global, do macro, da agregação, da busca do comum, das interfaces, da complementariedade nas várias áreas do conhecimento.

\section{FIGURA 2}

\section{A bordagem sistêmica}

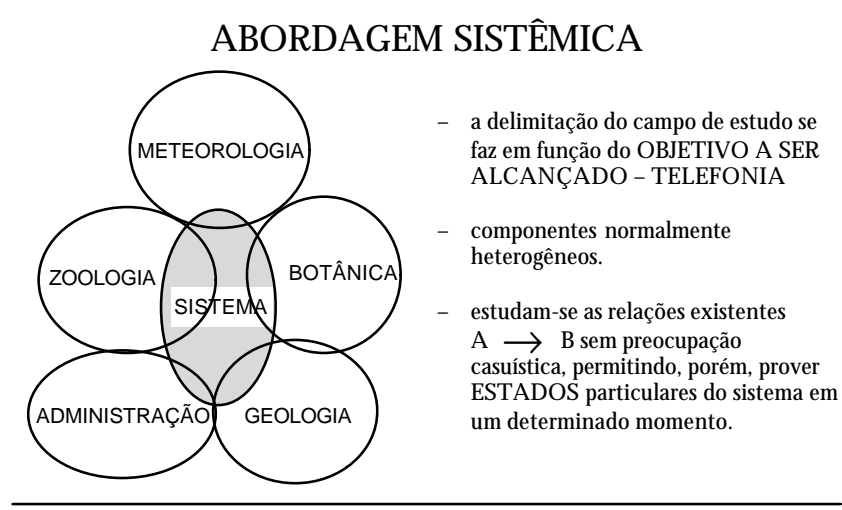

Esta nova abordagem é reforçada na II Guerra M undial, quando as equipes trabalhavam interdisciplinarmente, com especialistas originários de várias áreas, para equacionar os complexos problemas surgidos naquele período. E aí, emergiu a T eoria G eral dos Sistemas (T GS), como um instrumento apropriado para lidar com a "complexidade organizada" e as idéias comuns às várias disciplinas ou ciências.

0 primeiro anúncio da TGS foi em 1945, apesar de em 1937 ter sido apresentado um artigo no Seminário de Filosofia de $\mathrm{C}$ harles M orris, na U niversidade de C hicago.

Pai da idéia: Ludwig von Bertalanffy (1901-1972) austríaco, biólogo, radicado no Canadá, professor da U niversidade de A Iberta, em Edmonton (Canadá). N 0 prefácio do seu livro T eoria $\mathrm{G}$ eral dos Sistemas, ele escreve:

"O que pode ser obscurecido nesses desenvolvimentos por mais importantes que sejam - é o fato de que a teoria dos sistemas consiste numa ampla concepção que transcende muito os problemas e exigências tecnológicas, é uma reorientação que se tornou necessária na ciência em geral e na gama de disciplinas que vão da física e da biologia às ciências sociais, e do comportamento à filosofia. É uma concepção operatória, com graus variáveis de sucesso e exatidão, em diversos terrenos, e anuncia uma nova compreensão do mundo, de considerável impacto"...

N o mesmo prefácio, Bertalanffy continua, complementando com uma observação de Simon (1965):

“U ma introdução a um campo de conhecimento que está rapidamente se desenvolven do consiste em grande parte na história de seus conceitos. $\mathrm{N}$ ão é, portanto, inadequado que o presente trabalho seja constituído de estudos escritos ao longo de um período de cerca de 30 anos.

0 livro apresenta assim a teoria dos sistemas não como uma doutrina rígida (o que atualmente não é), masem seu movimento e no desenvolvimento de suas idéias, que, é de esperar, podem servir de base para ulteriores estudose pesquisas."

Por sua vez, A ckoff (1959) complementa: "Estamos participando do que é provavelmente o mais amplo esforço para chegar a uma síntese do conhecimento científico como jamais foi feita".

Como pode ser observado, da "física" subatômica à "história" há um acordo sobre a necessidade de reorientação da ciência. Para Bertalanffy, as realizações 


\section{A compreensão da sociedade da informação}

da tecnologia moderna reforçam esta tendência. o conceito de sistema, embora o termo "sistema" não tenha sido empregado até aquela data, tem uma longa história. Sob a designação de "filosofia natural", pode-se encontrá-lo em N icolau de Cusa (De ludo globi, 1463) quando explicita a "coincidência dos opostos" e a "unidadena diversidade"; e em vários outros autores, como Köhler (1924), Lotka (1925).

A urélio Peccei - um dos fundadores do Clube de Roma -, em seu livro $C$ em páginas para o futuro, resume, por meio de uma representação, a interdependência e a interação das diversas áreas:

FIGURA 3

\section{Á reas de interdependência*}

V isão muito simplificada e esquematizada da rede de fatores objetivos que interagem entre elese com os fatores humanos e sociais que não estão representados na ilustração. Resultam daí milhares de pontos nodais, entre eles vários críticos que costituem a problemática que devemos todos enfrentar, do nível local ao global.

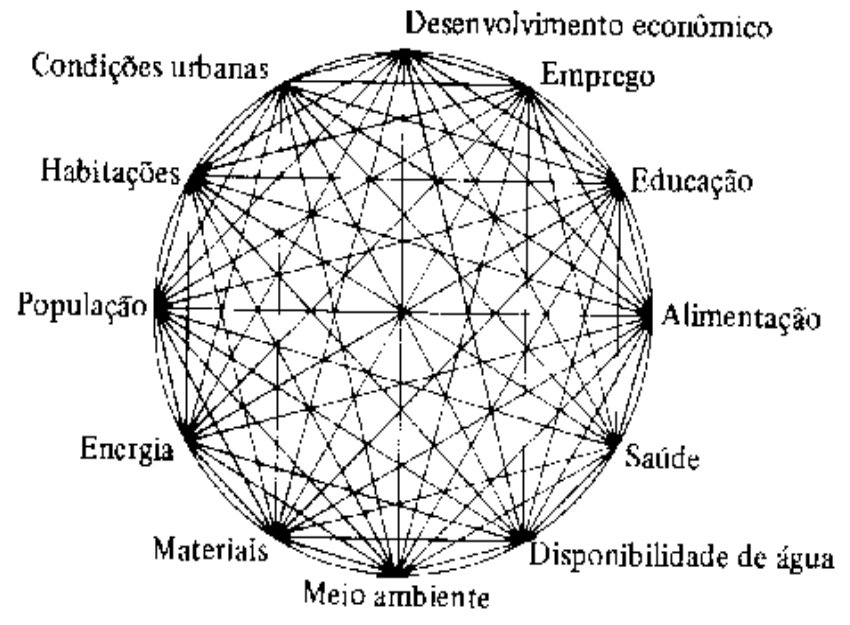

* Adaptado de The State of the Planet, editado por Alexandre King Pergamon Inernational Library, Oxford, 1980.

Como se pode constatar, a idéia da complementariedadee da unificação das ciências éantiga. Bertalanffy já a estudava antes da II Guerra.

Em 1954, motivado pelo sucesso de outras doutrinas general istas dos anos 40, como a cibernética, a teoria dos jogos, a teoria da informação, el e se une a outros cientistas - Kenneth Boulding (economista), Ralph Gerard (filósofo) e A natol Rapoport (matemático) - , e fundam a
Society for $G$ eneral Systems Research, na reunião anual da A ssociação A mericana para o Progresso da C iência. Logo após, outros vieram, como Leslie W hite, da A ntropologia; da Psicologia: A Ilport e Piaget; da Biologia: Paul W eiss, Pattee, James M iller; da Psiquiatria: Rizzo e Gray; da Linguística: N oam Chomsky; da Engenharia: K lir e Polak; da Sociologia: M erton e Sorokin; da Política: Churchman, e muitos outros como: Herbert Simon, da Psicologia; A rthur Koestler, jornalista húngaro; Rene Jules Dubos, francês, microbiologista nos EU A ; H enri M arie Laborit, neurologista francês; Jacques $M$ anod, bioquímico francês; Ervin Lazslo; Zerbst; Forrester e todo o "Clube de R oma".

Estabeleceram-se vários grupos locais da "Sociedade" em vários centros dos Estados U nidos e, posteriormente, da Europa. V árias pesquisas e publicações apareceram, juntamente com a revista $M$ athematical Systems T heory.

\section{C aracterísticas da T eoria}

Na compreensão da abordagem sistêmica são determinantes alguns conceitos e características, principalmente a complexidade, a hierarquia dos sistemas e as configurações principais:

a) Complexidade: é demonstrada pelo número de interações, articulações e interdependência entre os elementos de um sistema presentes em uma situação. A maioria das situações e problemas, seja qual for a sua extensão e conteúdo, provém de múltiplas causas e de variáveis interdependentes, resultantes da interação de diferentes fatores.

b) H ierarquia dos sistemas: a partir da complexidade que apresentam os diferentes sistemas e após várias propostas para o estabelecimento de uma ordem hierárquica, como a proposta de K oestler (1967) baseada na linguagem verbal, ou nas idéias semimatemáticas, como a de Simon (1965) relacionada à teoria das matrizes e outras apoiadas na teoria dosgráficos, da lógica matemática etc., K enneth Boulding (1956) estabeleceu uma hierarquia para os sistemas, partindo das estruturas mais simples para as mais complexas:

1 - sistema estático ou das estruturas estáticas, como os átomos, os cristais, mapas da terra etc.;

2 - sistema dinâmico simples (relojoaria) com mecanismos predeterminados: relógios, alavancas, sistemas solares, motores a vapor, dínamos etc.;

3 - sistema cibernético simples, com mecanismo de controle, utilizando a comunicação, retroação, volta ao 
estado de equilíbrio, como termostato, servomecanismos, mecanismo homeostático nos organismos;

4 - sistema aberto, com fluxo de matéria, insumos, metabolismo, como a célula, os rios, as chamas etc.;

5 - sistema da vida vegetal (organismos inferiores), em que as células são formadoras das sociedades de raízes, folhas, sementes, sucessão do germe, função reprodutiva;

6 - sistema da vida animal, com crescente importância da circulação de informação, da evolução de receptores, do desenvolvimento dos órgãos sensoriais, recebendo informações (olhos, ouvidos etc.) do sistema nervoso, da aprendizagem, mobilidade, comportamento e começo da consciência;

7 - sistema homem ou da vida do ser humano, com capacidade de auto-reflexão, memória, fala, desenvolvimento de habilidades, simbolismos, autoconsciência, individualidade e mundo, passado e futuro, comunicação pela linguagem etc.;

8 - sistema sociocultural ou da organização social, com populações de organismos, organizações, indivíduos, comunidades determinadas por símbolos ou culturas, indivíduos a desempenhar papéis, canais de comunicação etc.;

9 - sistema simbólico, com linguagem, lógica, matemática, ciências, arte, moral, utilizando algoritmos, regras do jogo etc. N este último nível, poder-se-ia incluir o sistema mundo virtual, estabelecido por diferentes relações quanto ao tempo, distância, interfaces, comunicação, localização etc.

c) C onfigurações principais os sistemas possuem as mais diferentes configurações, podendo ser macro ou microscópicos; biológicos ou mecânicos; sociais, ecológicos ou físicos; naturais ou artificiais. A TGS vê o global, e não o atomístico; vê o complexo, enão o simples; vê as interações entre as partes, e não as causalidades lineares. 0 denominador comum dos sistemas é a complexidade, a interação entre as partes componentes os elementos - e a existência de um comportamento, de uma finalidade, de uma conduta.

A riqueza de um sistema vem das interconexões, das interfaces entre os elementos, e não do número de elementos; não éum simplesagregado, amontoado ou soma de partes. U m sistema compreende um arranjo, em interações e transformações, demonstrando desmensurada potencialidade de modos de ser.
0 sistema tem também um ciclo de vida: nasce, amadurece e morre, a não ser que seja reformulado, dentro de um comportamento - conduta - criativo e inovador, não se deixando ir pelo mais provável, simplificado, acomodado e repousante, que termina por levá-lo à entropia ou até mesmo ao caos (a entropia pode levar ao caos, mas não é o caos).

O bserva-se também que o contorno do sistema, o tamanho ideal, o objetivo e a finalidade são atributos, e não propriedadesintrínsecas. 0 dinamismo dossistemas pode levá-lo às emergências (novas propriedades de dentro para fora) ou à sua redução.

V árias outras características podem ser verificadas, porém estas são as relacionadas a esse documento, convergindo para uma definição de sistema como:

"Sistema é um conjunto de elementos com funções próprias (não intercambiáveis) que interagem (trocam influências) e agem em conjunto (organizadamente) para atingir um ou mais objetivos".

\section{AS TENDÊNCIAS ATUAIS}

A simples compreensão de que as instituições sociais e o mundo são sistemas, e não somas de átomos físicos ou sociais, ou de que os diversos estágios por que passou 0 mundo consistem em sistemas chamados "civilizações", que seguem princípios gerais, têm características próprias dos sistemas, implica um redirecionamento da conduta do homem perante os desafios do momento.

0 mundo virtual fez profundasalterações, principalmente nas concepções de espaço e tempo. N ão há mais distância, território, domínio e espera: vive-se o aqui e o agora. 0 virtual usa novos espaços, novas velocidades, sempre problematizando e reinventan do o mundo. A virtualidade leva também a passagem do interior ao exterior, e do exterior ao interior - os limites não mais existentes e há um compartilhamento de tudo. 0 s dois bens primordiais do ponto de vista econômico com características próprias e diferenciadas dos outros bens são a informação e o conhecimento, pois o seu uso não faz com que acabem ou sejam consumidos.

Q uando são utilizados, há um processo de interpretação, de interligação, de complementariedade, promovendo um ato de criação e invenção. 0 uso da virtualização, cada vez mais presente no nosso cotidiano, amplia as potencialidades humanas, criando novas relações, novos conhecimentos, novas maneiras de aprender e de pensar. 


\section{A compreensão da sociedade da informação}

0 grande desafio é conseguir que, nesta velocidade e desempenho, o virtual não interfira na identidade cultural dos povos, fazendo com que um projeto de "civilização centrado sobre os coletivos pensantes" possa conter este risco, já que o mundo virtual é inevitável.

A convergência de opiniões de autores de diferentes áreas do conhecimento sobre as mudanças atuais e as megatendências, como A Ivin Toffler, Fritjof Kapra, Stafford Beer, I oneji M asuda, Peter D rucker, Lorenzo V ilches, Pierre Lévy, ThomasK uhn, Karl Popper e M anuel Castells, corroboradas pelosfatos do dia-a-dia, demonstra, de maneira impactante, as mudançasna área específica da informação e da constituição de seus sistemas e das suas organizações.

Em um quadro comparativo, abordando as organizações sociais, tem-se uma compreensão mais objetiva das diferenças entre uma organização da Segunda O nda - da sociedade industrial - e a organização moderna, da sociedade da informação e do conhecimento:

\begin{tabular}{|c|c|}
\hline $\begin{array}{l}\text { EMPRESA DA SOCIEDADE } \\
\text { INDUSTRIAL }\end{array}$ & $\begin{array}{l}\text { EMPRESA DA SOCIEDADE } \\
\text { DA INFORMAÇÃO }\end{array}$ \\
\hline Enfoque analítico/atomístico. & Enfoque macro/holístico. \\
\hline $\begin{array}{l}\text { Individualismo/predomínio/ } \\
\text { distanciamento entre as pessoas. }\end{array}$ & $\begin{array}{l}\text { Igualdade de direitos/ } \\
\text { compartilhamento/ } \\
\text { participação. }\end{array}$ \\
\hline $\begin{array}{l}\text { A utoridade centralizadora/ } \\
\text { paternalista/autocrática. }\end{array}$ & $\begin{array}{l}\text { A utoridade adulta/ } \\
\text { facilitadora/democrática. }\end{array}$ \\
\hline $\begin{array}{l}\text { Continuidade num único nicho } \\
\text { profissional. Especialização } \\
\text { excessiva. }\end{array}$ & $\begin{array}{l}\text { O pções múltiplas. Liberdade } \\
\text { de escolha. V isão } \\
\text { generalizada. }\end{array}$ \\
\hline $\begin{array}{l}\text { Economia de escala/tendência ao } \\
\text { gigantismo e à centralização. }\end{array}$ & $\begin{array}{l}\text { D escentralização, } \\
\text { resguardando-se a integração. }\end{array}$ \\
\hline V alorização da quantidade. & $\begin{array}{l}\text { Valorização da qualidade } \\
\text { associada à quantidade. }\end{array}$ \\
\hline $\begin{array}{l}\text { Empresário avesso ao risco. } \\
\text { Busca de protecionismo. }\end{array}$ & $\begin{array}{l}\text { Empresário empreendedor, } \\
\text { criativo e competitivo. }\end{array}$ \\
\hline A grande alavanca é o dinheiro. & $\begin{array}{l}\text { A grande alavanca é a } \\
\text { informação/o conhecimento/ } \\
\text { a educação. }\end{array}$ \\
\hline $\begin{array}{l}0 \text { sucesso é garantido pelo poder } \\
\text { de investimento em máquinas e } \\
\text { instalações. }\end{array}$ & $\begin{array}{l}\text { A mente humana é o grande } \\
\text { software. } 0 \text { computador é o } \\
\text { grande hardware. }\end{array}$ \\
\hline
\end{tabular}

A pós essas considerações, a sociedade da informação e do conhecimento pode ser caracterizada sinteticamente, por alguns itens, como:

- a grande alavanca do desenvolvimento da humanidade é realmente o homem;
- a informação é um produto, um bem comercial;

- o saber é um fator econômico;

- as tecnologias de informação e comunicação vêm revolucionar a noção de "valor agregado" à informação;

- a distância e o tempo entre a fonte de informação e o seu destinatário deixaram de ter qualquer importância; as pessoas não precisam se deslocar porque são os dados que viajam;

- a probabilidade de se encontrarem respostas inovadoras a situações críticasé muito superior à situação anterior;

- as tecnologias de informação e de comunicação converteram o mundo em uma "aldeia global" (MacLuhan);

- as novas tecnologias criaram novos mercados, serviços, empregos e empresas;

- astecnologias de informação e comunicação interferiram no "ciclo informativo", tanto do ponto de vista dos processos, das atividades, da gestão, dos custos etc.:

- o próprio usuário da informação pode ser também 0 produtor ou gerador da informação;

- registro de grandes volumes de dados a baixo custo;

- armazenamento de dados em memórias com grande capacidade;

- processamento automático da informação em alta velocidade;

- recuperação de informação, com estratégias de buscas automatizadas;

- acesso às informações armazenadas em bases de dados em vários locais ou instituições, de maneira facilitada;

- monitoramento e avaliação do uso da informação.

Enfim, como explicita A Ivin T offler (1995) no seu livro C riando uma nova civilização:

“Por trás dessa monumental realocação de poder, reside uma mudança no papel, na significação e na natureza do conhecimento". 


\section{M aria A lice G uimarães B orges}

\section{OS DESAFIOS DO MOMENTO}

Em 1972, C. W . Churchman em seu livrol ntrodução à T eoria dos Sistemas, aponta alguns problemas da humanidade, que até hoje permanecem atuais e desafiadores:

"Suponhamos que comecemos fazendo a lista dos problemas do mundo de hoje que em princípio podem ser resolvidos pela moderna tecnologia.

Em princípio, temosa capacidade tecnológica dealimentar, abrigar e vestir adequadamente todos os habitantes do mundo.

Em princípio, temosa capacidadetecnológica de assegurar adequado cuidado médico para todos os habitantes do mundo.

Em princípio, temosa capacidade tecnológica de oferecer suficiente educação a todos os habitantes do mundo para gozarem de uma vida intelectual madura.

Em princípio, temos a capacidade tecnológica de colocar fora da lei a guerra e instituir sanções sociais que evitarão a deflagração de uma guerra ilegal.

Em princípio, temos a capacidade de criar em todas as sociedades uma liberdade de opinião e uma liberdade de ação que reduzirão ao mínimo os constrangimentos ilegítimos impostos pela sociedade ao indivíduo.

Em princípio, temos a capacidade de desenvolver novas tecnologias, que libertarão novas fontes de energia e poder para atender às emergênciasfísicas e econômicas em todo o mundo.

Em princípio, temos a capacidade de organizar as sociedades do mundo atual para realizar planos bem desenvolvidos a fim de resolver os problemas da pobreza, saúde, educação, guerra, liberdade humana e 0 desenvolvimento de novos recursos.

Se o ser humano tem a capacidade de fazer todas essas coisas, por que não as faz? H averá al gum perverso traço de caráter que corre através da espécie humana e torna um ser humano indiferente à condição do outro? Estamos essencialmente em face de um tipo de degradação moral que nos permite ignorar nosso vizinho em razão de nosso próprio interesse?

O u existe al guma razão mais profunda e sutil pela qual, a despeito de nossa enorme capacidade tecnológica, não estamos ainda em condições de resolver os principais problemas do mundo? Se passarmos os olhos sobre a lista dos problemas, há um aspecto deles que logo se torna evidente: esses problemas são interligados e se sobrepõem parcialmente. É claro que a solução de um problema tem muito a ver com a solução de outro.

São tão interligados e imbricados de fato que não é de modo algum claro por onde devemos começar. Suponhamos, por exemplo, que concebemos a idéia de que o primeiro problema a ser solucionado é o de alimentar, abrigar e vestir adequadamente todos os habitantes do mundo. Como começaríamosa resolver este problema? A capacidade tecnológica existe. Podemos produzir 0 alimento necessário para chegar a este resultado e os materiais de construção que ofereceriam abrigo e os tecidos que vestiriam o indivíduo. Então por que não fazemos isso? A resposta é que não estamos organizados para fazê-lo."

Como atuar diante deste desafio e sobre esta "causa" que parecem tão simples, mas que na verdade são tão complexos se "não estamos organizados para fazê-lo" e não temos como resolvê-los?

Vários foram os caminhos seguidos pelas nações do 0 cidente e do 0 riente, ideologicamente opostas ou juntas, onde se somam esforçose osresultadosainda são pequenos.

M as a resposta deverá vir da própria ciência, através de alguns de seus principais pensadores, como D escartes e Pascal, M anuel Castells, Thomas Kuhn, Karl Popper e outros.

A s teses são explicativas, mas não são prognósticas.

De acordo com Thomas Kuhn (1962), a ciência "normal" segue procedimentos e normas. Somente quando há uma ruptura (revolução científica), há o aparecimento de novos esquemas ou novos paradigmas:

"M uitas realizações da biologia molecular, da cibernética e de outros campos mostraram a ciência 'normal', isto é, os esquemas conceituais admitidos em caráter monolítico ... mas uma 'revolução científica' define-se pelo aparecimento de novos esquemas ou paradigmas conceituais. Há um deslocamento nos problemas observadose estudadose uma mudança das regras da prática científica. A s primitivas versões de um novo paradigma são na maioria das vezes toscas, resolvem poucos problemas e as soluções dadas aos problemas individuais estão longe de serem perfeitas. Há uma profusão e competição de teorias, cada uma das quais limitadas no que diz respeito ao número de problemas a que se referem e à solução 


\section{A compreensão da sociedade da informação}

elegante daqueles que são levados em consideração. Contudo, o novo paradigma abrange novos problemas, especialmente os que anteriormente eram rejeitados como 'metafísicos'". A partir dessa contribuição de Kuhn, Bertalanffy complementa:

“O problema do sistema é essencialmente o problema das limitações dos procedimentos analíticos na ciência clássica. Isto costuma ser expresso em enunciados semimetafísicos, tais como "evolução emergente", ou "o todo é mais do que a soma de suas partes", mas tem uma clara significação operacional.

"Procedimento analítico" significa que uma entidade pode ser estudada resolvendo-se em partes e por conseguinte pode ser constituída ou reconstituída pela reunião destas partes, em um todo."

Rompendo com uma perspectiva conservadora, tem-se 0 contraponto da filosofia do aleatório:

"O nde se permanece em uma filosofia do aleatório, onde se está ligado a leis pobres com determinação unívoca e fixa... o pluralista age bem, ao fazer observar ao dialético a pobreza de suas estruturas e o erro sempre recomeçado de sua prospectiva". (M ichel Serres - H ermès I)

Reunindo-se estas grandes contribuições às mudanças necessárias à ciência, no processo de transformação e resposta aos problemas e desafios, surge Popper como a síntese e o marco na filosofia da ciência, trazendo suas idéias como a base de operação na atividade científica, sendo em resumo uma filosofia de ação.

Popper acredita que o conhecimento só pode progredir graças à crítica, mediante argumentos muito fortes. A filosofia é uma atividade necessária, para se admitir uma série de pressupostos, a partir de um exame crítico dospressupostos, dasteorias, das proposições, das asserções - que são as entidades lingüísticas mais importantes do Terceiro M undo.

O s argumentos constituem sua força orientadora, como poder de persuasão, com grandiosidade, autoconfiança e rigor lógico.

No seu livro C onhecimento objetivo: uma abordagem evolucionária, ao expor a "teoria da mente objetiva", estabelece o pluralismo e a tese dos três mundos. Considera o primeiro mundo, o material ou dos estados materiais; o segundo mundo, o mental ou dos estados mentais; terceiro mundo, o mundo dos "inteligíveis" ou das idéias no sentido objetivo.
A s relações causais entre os três mundos têm o segundo mundo como mediador, que estabelece um "elo indireto" entre os outros dois.

0 primeiro e terceiro mundos são externos, só percebidos pelo segundo, e só se pode entender o primeiro e segundo mundos por meio do terceiro mundo, apreendendo-se os conteúdos de pensamentos objetivos.

0 terceiro mundo existe "em realidade": é produto dos homens, autônomo e leva à "obra original" e "criativa".

o "processo" é constituído pela seqüência de estados precedentes, e o trabalho de criticar o estado al cançado é que constitui a "atividade".

A atividade pode ser representada por um esquema geral de solução de problemas pelo método de conjecturas imaginativas e de crítica, também chamado M étodo de Conjectura e R efutação, representado por:
$\mathrm{P} 1 \longrightarrow \mathrm{TT} \longrightarrow \mathrm{EE}$ P2...n, onde
$\mathrm{P1}=$ Problema (de partida)
$\mathrm{TT}=$ T eoria experimental
$\mathrm{EE}=$ Eliminação de erro
P2 = Tentativa de solucionar o problema e/ou início de uma resolução de um novo problema.

A firma, ainda, que é necessário mais do que uma análise do problema para a sua compreensão real, conseguindo manejar unidades estruturais do terceiro mundo.

Popper, entre tantas proposições, explicita que "a compreensão éa meta da humanidade" e talvez seja esta a resposta ao questionamento de Churchman. Compreensão que virá da contribuição de cientistas que são fundamentais no estudo desta sociedade globalizada e centrada no uso e na aplicação da informação e do conhecimento, como escreve M anuel Castells em sua trilogia, iniciada pelo livro A Sociedade em Rede (1999).

\section{CONCLUSÃ O}

A informação sempre foi o insumo básico do desenvolvimento. Q uando o homem associou a fala e a imagem e criou a escrita, ele permitiu a transmissão e a armazenagem de informação. A imprensa de G utenberg, no século $X V$, o telefone, o rádio, a tel evisão e agora as tecnologias da informação e da comunicação, que revolucionaram os séculos $X I X$ e XX, acel eraram 0 acesso e o intercâmbio de informações. Estes diversos meios de comunicação, em vez de se excluírem, potencializam-se, mutuamente. $\mathrm{N}$ as vésperas do século XXI, o mundo está se preparando para dar mais um salto, através das novas tecnologias e das novas redes. 
Tanto do ponto de vista dos benefícios sociais que trará aos cidadãos, à comunidade, às nações, bem como dos benefícios econômicos que advirão com a ampliação das oportunidades de educação, da formação profissional, da diminuição do desemprego, das novas oportunidades de mercado, do desenvolvimento dos setores produtivos, conclui-se que a sociedade da informação e do conhecimento é uma realidade. É uma resposta à dinâmica da evolução, ao crescimento vertiginoso de experiências, invenções, inovações, dentro de um enfoque sistêmico onde a interdisciplinariedade é fator determinante - em franco desenvolvimento e renovador, principalmente, para países mais pobres, mais despreparados, onde se tornou uma esperança de crescimento e desenvolvimento para poderem se aproximar dos países economicamente prósperos, porém dentro de uma perspectiva de renovação de ideal, como retrata o ministro da Ciência e da T ecnologia de Portugal, José M ariano Gago (maio, 1997) na apresentação do Livro Verde para a Sociedade da Informação em Portugal:

"A s sociedadesnão perdem o seu lastro histórico. 0 desejo da Sociedade da Informação e do Conhecimento não faz uma sociedade nova: é antes a renovação de um ideal antigo, a proclamação de uma liberdade desejada, a fome de modernidade e de justiça, como se, de repente, as possibilidades técnicas tornassem insuportáveis os entraves burocráticos, a sufocação autoritária, a privação de informação e de saber".

A snovastecnologias, os novos mercados, as novas mídias, os novos consumidores desta era da informação e do conhecimento conseguiram transformar o mundo em uma grande sociedade, globalizada e globalizante; mas 0 homem, diante dessa nova realidade, continua o mesmo: íntegro na sua individualidade, na sua personalidade, nas suas aspirações, na defesa de seus direitos, na busca da sua felicidade e de suas realizações, e no comando desta mudança, como o único ser dotado de vontade, inteligência e conhecimento capaz de compreen der os desafiose definir os passos que direcionarão seu próprio futuro.

\section{REFERÊNCIAS BIBLIOGRAFICAS}

BERTA LANFFY, Ludwig von. T eoria geral dos sistemas. Petrópolis : Vozes, 1975. 351p.

CA STELLS, M anuel. A sociedade em rede. São Paulo : Paz e Terra, 1999. v. 1.

CHURCHMAN, C. W. Introdução à teoria dos sistemas. Rio de Janeiro: V ozes, 1972. 309 p. cap. 1, p. 17-18.

LÉVY, Pierre. 0 que é virtual? São Paulo : Editora 34, 1996. 157 p.

MA SUDA, Yoneji. A sociedade da informação como sociedade pós-industrial. Rio de Janeiro : Editora Rio, 1982.

M A T T OS, João M etello. A sociedade do conhecimento. Brasília : UnB, 1982. $512 \mathrm{p}$

NORA, Simon; MINC, A lan. A informatização da sociedade. Rio de Janeiro : Fundação G etúlio V argas, 1980. 171 p.

PEC CEI, A urélio. C em páginas para o futuro. Brasília : UnB, 1981. 120 p.

POPPER, Karl Raymond. Conhecimento objetivo: uma abordagem evolucionária. São Paulo : EDUSP, 1975. 394 p.

PORTUGAL. M inistério da Ciência e Tecnologia. Livro Verde para a Sociedade da Informação em Portugal. Lisboa : M issão para a Sociedade da Informação, 1997. 125 p.

TOFFLER, A Ivin. C riando uma nova civilização: a política da terceira onda. Rio de Janeiro : Record, 1995. 142 p.

VICA RI, Rosa M aria. Sociedade da Informação: políticas em desenvolvimento no exterior. Porto A legre: U FRG S/ Instituto de Informática, 2000.

VILCH ES, Lorenzo. G lobalização, mídia e cultura contemporânea. Campo Grande : Letra Livre, 1997.

A rtigo aceito para publicação em 12-10-2000 